\title{
English as a Career Subject: Analysis of Nepalese Students' Expectations, Achievements and Reflections
}

\author{
Binod Luitel $^{1} \&$ Kamal Kumar Poudel ${ }^{2}$ \\ ${ }^{1}$ Tribhuvan University, Research Centre for Educational Innovation and Development (CERID), Balkhu, \\ Kathmandu, Nepal \\ ${ }^{2}$ Tribhuvan University, Department of English Education, Mahendra Ratna Campus, Tahachal, Kathmandu, \\ Nepal \\ Correspondence: Kamal Kumar Poudel, Tribhuvan University, Department of English Education, Mahendra \\ Ratna Campus, Tahachal, Kathmandu, Nepal.
}

Received: March 7, 2021

doi: $10.5539 /$ elt.v14n5p30
Accepted: April 12, 2021

Online Published: April 15, 2021

\begin{abstract}
The present study explores the novice Master's degree pass-outs' initial expectations for learning English as a career subject (ECS), their achievements from learning it and their reflections on the achievements. Ten novice Master's pass-outs' (NMPOs') narrative biographical stories were obtained by applying a questionnaire via the e-mail. The data obtained in the form of the NMPOs' stories were analyzed using the content analysis technique. It was found that the mismatches between the initial expectations and the final achievements outnumbered the links between them. The expectations the NMPOs have achieved are mostly of the integrative kind and those they have not are of the instrumental kind - the latter being an area of their dissatisfactions. Drawing from the results, a future direction suggested to the concerned authority is that ECS should be considered in the light of education as an investment for life.
\end{abstract}

Keywords: English as a career subject, expectation, achievement, motivation, human capital

\section{Introduction}

Harmer (2008) claims that learners learning English almost universally have some reasons and diverse purposes. $\mathrm{He}$ states, "Some students, of course, only learn English because it is on the primary or secondary level curriculum, but for others, studying the language reflects some kind of a choice" (p. 11). What he observes is also true in the Nepalese context where English is taught as a compulsory subject from the primary level up to the Bachelor's level, so the students are compelled to learn English as a compulsory subject as per the curricular provision. However, when the students of higher studies choose learning it as an optional subject, the choice reflects their motivation because, arguably, they, as adult learners, have now grown to be autonomous to make choice of the subject for their career development.

In this connection, it can be argued that in making a choice, one has some kind(s) of expectation - be it overt or covert. Throughout the study reported in this paper, we have concentrated on the expectations the novice Master's pass-outs (NMPOs) in English from the Faculty of Humanities and Social Sciences had set as they had begun learning English as an optional subject - a subject which offers English literature as the curricular core. They had studied English rather than any other subject as an academic course, hence as a career subject, in college education. The acronym NMPOs has been employed to refer to the students who have completed their formal classroom-based study of Master of Arts (M.A.) program in English ( $4^{\text {th }}$ Semester) and are doing their thesis as a partial fulfillment of the requirement of their Master's degree, or have recently (not more than two years) fully completed the degree but have not yet been engaged in the kind of profession they have been longing for as Master's degree holders in English.

As argued above, we assume that the NMPOs did have certain expectations at the time they had decided to study ECS at the cost of some other options open to them when they had joined Bachelor's degree. In this study, those beginners have been termed 'Bachelor's degree candidates' (BDCs). As a process of higher education in Nepal, English majors, like the students who specialize in any other discipline, enter as BDCs and depart as NMPOs. In this study, the duration between these two statuses of the English majors has been referred to as their 'academic 
path' (cf. Figure 1). Having crossed the academic path, the then-BDCs have now grown to be the NMPOs. The NMPOs' stories have been the data-text for the study.

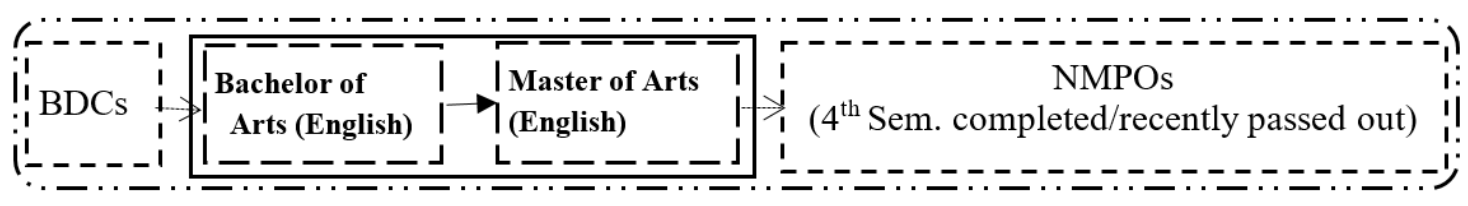

Figure 1. Academic path (for English majors)

This study aims to find what factors had motivated the NMPOs to opt for ECS when they were BDCs, and how far they have achieved their expectations as they are NMPOs now; and also, how they reflect on their achievements from learning ECS. In other words, it aims at analyzing the match/mismatch relationships between the BDCs' expectations and achievements as NMPOs now. More specifically, the study sets out to answer the following research questions.

1) As BDCs, what expectations did the now-NMPOs have for learning ECS?

2) What achievements have now they attained as NMPOs?

3) Are the NMPOs satisfied with their achievements?

- If so, why?

- If not, why?

\section{Review of Literature}

The relevant literature, theoretical as well as empirical, has been reviewed and presented under four broad themes which include: (i) motivation, (ii) human capital theory, (iii) foreign language learners' expectations in the wider context, and (iv) English language learners' expectations in the local context.

\subsection{Motivation: A Theoretical Perspective}

In the context of foreign/second language teaching and learning, motivation is regarded as a significant determinant associated with learning achievement. The central essence of all motivation theories is the explanation of why people think and behave in the way they do. Through a survey, Dörnyei and Ushioda (2011) conclude that, regarding motivation, most researchers agree that it concerns the direction and magnitude of human behaviour (emphasis in the original). Therefore, according to them, motivation determines the individual's choice of a particular action, the persistence with it and the effort extended on it. As they further clarify, motivation essentially determines why people decide to do something; how long they are willing to sustain the activity; and 'how hard they are going to pursuit it' (p. 4). Similarly, they recognize motivation as the cause, effect or process and theorize its function in a cyclical relationship with learning, with the possibility of being positive as well as negative, hence: (i) high motivation $\rightarrow$ high achievement $\rightarrow$ high motivation' (positive cycle), and (ii) low motivation $\rightarrow$ low achievement $\rightarrow$ low motivation (negative cycle) (p. 6). This suggests that, besides choice taking for learning, motivation causes higher achievement; and, in turn, higher achievement creates further motivation. As Lamb (2016) investigates, depending on particular circumstances, occasional rises and falls in the long-term motivational trajectories of second language motivation can also occur. However, strategies can be adopted for sustaining motivation among learners, as pointed out by Karimi and Zade (2018), who state that effective teachers can significantly sustain second language learners' motivation by the use of their motivational strategies.

A distinction is generally made between intrinsic and extrinsic motivation. Pleasure and self-satisfaction in the task shape intrinsic motivation. To quote from Noels et al. (1999), "intrinsic motivation refers to motivation to perform an activity simply for the pleasure and satisfaction that accompany the action" (p. 24). Extrinsic motivation, on the other hand, is associated primarily with "those behaviours that are performed not because of inherent interest in the activity, but in order to arrive at some instrumental end" (Noels et al., 1999, p. 24). Thus, when learners are intrinsically motivated, they are engaged in the activity because they inherently love doing so; but when they are extrinsically motivated, they are tempted towards the task by some 'exogenous factors' (Abrar-Ul-Hassan, 2014). Nonetheless, these two kinds of motivation sometimes reveal an anti-proportional relationship. According to Sieglová (2019), "when students are prompted by external forces, intrinsic motivation decreases, whereas when autonomy and competence is enhanced, intrinsic motivation rises" (p. 431).

Further, in the context of foreign/second language learning, distinctions are also made between integrative and instrumental motivation. In Dörnyei's (1974) words, "the former [integrative] is associated with a positive disposition toward the L2 group and the desire to interact with and even become similar to valued members of 
that community" (p. 247). He continues, "The latter [instrumental] is related to the potential pragmatic gains of L2 proficiency, such as getting a better job or a higher salary".

Simply stating, when a learner of another (foreign/second) language is integratively motivated s/he puts a high value to the language and is tempted to interact with the speakers of the language using it. On the contrary, an instrumentally motivated learner is tempted by the utilitarian benefits to be achieved after gaining proficiency in the language, which are associated with the fulfillment of personal needs

\subsection{Human Capital Theory}

Human capital theory views people as capital for development and education as an investment. From this perspective, as Nafukho et al. (2004) clarify, schooling and education are deliberate investments for preparing labour force and increasing the productivity of individuals and organizations. Human capital theory, therefore, essentially proposes that education should be used as a means of increasing the productivity of individuals. Following this premise, individuals are involved in learning through formal education so that they will earn a certain amount of additional income utilizing their skills gained through the learning after their education or training. A literature on labour economics makes a claim of a general finding which shows that each year of additional education results in the increase of wages by $5-15 \%$ (Lindahl \& Canton, 2007).

Human capital theory implies that all forms of human behavior, activity or action is invested for returns - most preferably in the form of financial benefits. The central essence of human capital theory, therefore, quite closely approximates that of instrumental motivation. Nonetheless, this theory has rather little connection, if any, with the other types of learner motivation mentioned above.

\subsection{Foreign Language Learners' Expectations: Wider Context}

There is quite a good body of literature on foreign language learning motivation, expectations and reasons, learner and teacher beliefs and attitudes explored from various perspectives, mainly including gender, age and the level of study. In this regard, we present a representative glimpse of empirical studies conducted in three countries where English is a foreign language: Iran, Turkey and Egypt.

It is recognized that learner attitudes are a significant factor for the success or failure in learning a foreign/second language. Eshghinejad's (2016) study involving 30 Iranian university freshmen of English as a foreign language (EFL) (19 males and 11 females) leads to the advocacy that "the nature of language learning... depends primarily on learners' motivation and attitude to learning a target language" (p. 3). The major reasons for learning EFL explored from Iranian teachers and students were: love for English (English sounds beautiful or luxurious to them), furthering education (passing IELTS/TOEFL/GRE, university entrance, pursuing higher education up to the doctoral degree, and accessing resources for knowledge), getting higher and better-qualified jobs, communication with the native speakers of English as well as a wider range of people from other nationalities and relatives living there, immigration (to migrate to the English speaking countries), entertainment (reading books and magazines in English for pleasure, watching English movies, listening to English songs, surfing the net in English and travelling to the English speaking countries), social credit (English as a matter of prestige), and need (no English means functionally illiterate) and parental influence (Zarrabi, 2018).

Akçay et al. (2015) conducted a study on children learning foreign languages at private institudes in Turkey explored seven reasons/expectations for their learning those languages (in the order of priority): talking to foreigners/tourists, entertainment (songs, games, movies, etc.), having better grades at school, English being a global language, having a better job/earning more money, living/working abroad, and enjoying learning English.

Learner beliefs are also associated with learner expectations and motivation to learn EFL. In this respect, Daif-Allah (2012) claims that "accuracy of English and linguistic abilities are necessary tools that might determine the nature of their future careers as well as their social status in worldwide communities" (p. 25), and explores university English language learners' expectations and motivation attached with learning EFL in the Egyptian context. As the study demonstrates, around $90 \%$ of the participants were intrinsically motivated to learn English, while $85 \%$ of them were motivated to get a good job, $85 \%$ to know its speakers better; and $76 \%$ said they wanted to achieve English as a necessity. Although the study identifies similar beliefs between the male and female participants, statistically significant gender differences were found in terms of English language aptitude, learning and communication, and motivation and expectations.

\subsection{English Language Learners' Expectations: Local Context}

In the context of Nepalese ELT, the literature written in the English language is evidently a foreign literature. However, every year a substantial number of students are enrolled in higher education opting for English as a 
major subject with the implied supposition that learning English literature also means learning the English language.

Some relevant literature also exists locally. According to Bista (2011), the main purpose of teaching and learning EFL in the past was to enable learners to listen to the radio, to understand dialogues in movies, and to use it for communication. However, currently, the EFL teaching and learning inspirations in Nepal are characterized in terms of "charm and attraction" (Kandel, 2018), "craze for English" (Poudel, 2018), "mania" (Bista, 2011) and "dream" (a respondent in Kandel's study, 2018) among the learners themselves as well as the general public. English, a popular foreign language, is used as a medium of instruction in many schools, colleges and universities in Nepal (Bista, 2011).

One of the reasons for the increased number of privately owned educational institutes is the "mania" for English among the learners themselves and their parents/guardians (Bista, 2011). As Bista argues, colleges and universities are offering English language and literature courses as core and elective subjects to address this sort of English-mania. As he points out, the need for English language teaching and learning in Nepal includes enabling learners for communication with English users, and for English-based knowledge, ideas, skills and techniques, offering a medium of instruction for science, engineering, medicine and other technical institutes, and as the only medium of diplomatic relations with the outside world. Obviously, EFL learners' expectations are strongly linked with these needs, as they are learning the language with the optimism that their career space is created on this kind of 'need base'.

Arguing that B.Ed. first year students of English had some expectations for learning it, which, in turn, had an influence on their learning goals as well as motivation, Poudel (2016) identified seven reasons for learning it as a specialization subject: employability, international communication, academic success, self-improvement and social status, intrinsic purposes, social service, and pedagogic/professional skills.

Another empirical study has found out extreme attraction to the English language among learners of secondary level and higher studies. In a Kathmandu-based study involving the students of English representing the secondary, college and university levels as participants, Kandel (2018) investigated what he termed 'charm' and 'attraction' of the English language. He explored four major themes implied in the 'charm' and 'attraction': career development, knowledge expansion, global communication, and other (educational, socio-economic and professional) gains.

To sum up the section, there has been a good amount of research into the expectations of foreign language learners, particularly EFL, both internationally and nationally/locally but, as a gap, little, if any, research exists regarding the achievements and reflections of those students for learning it. One point of justifying this study is its focus on the gap.

\section{Methodology}

The study is underpinned by the qualitative approach, whereby the inquiry is "based on textual rather than numerical data" (Howitt, 2016, p. 534). It basically builds on the narrative inquiry technique of data collection which has been conceptualized in this study as "a way of doing research that focuses on the stories we tell about our lives" (Barkhuizen, 2015, p. 169). It is supposed that the NMPOs' personal narratives connect their past expectations for learning English to the present achievements and then to their reflections on the achievements. The detailed design of the research is presented under the headings below.

\subsection{Participant Selection Process}

The participants were selected purposively on convenience basis. Convenience sampling is recognized as "a method of sampling in which subjects or participants are selected for a research study based on how easy or convenient it is to reach or access them and based on their availability to participate" (Privitera \& Ahlgrim-Delzell, 2019, p. 239).

A total of ten NMPOs who had either just taken the exams of Master's degree fourth semester and were working on their thesis to fulfil the requirement of Master's degree from the Central Department of English, Tribhuvan University, or completed the degree fairly recently (not exceeding a two years' duration) were conveniently selected as the participants (cf. Table 1). In this connection, suggestions for participant selection were sought from the respective university teachers from the department. One of the teachers, to his credit, additionally co-operated with us by advising on the appropriateness of the participants to meet the purpose of our study, and then by providing further coordination during data collection (see Acknowledgement). His judgment regarding their easy availability and adequacy of the required information made the major basis for participant selection. In this sense, the participants were friends-of-a-friend conveniently available in Kathmandu valley. 
Table 1. Participant description

\begin{tabular}{|c|c|c|c|}
\hline $\begin{array}{l}\text { Participants } \\
\text { (Pseudonyms) }\end{array}$ & Gender & Degree (completed \& ongoing) & Employment status \\
\hline Bimala & Female & Master's degree & $\begin{array}{l}\text { Permanent English teacher (secondary } \\
\text { level) at a public school }\end{array}$ \\
\hline Deepak & Male & $\begin{array}{l}\text { Master's degree fourth semester } \\
\text { (Thesis just started) }\end{array}$ & No job \\
\hline Dev & Male & $\begin{array}{l}\text { Master's degree fourth semester } \\
\text { (Thesis ongoing) }\end{array}$ & English teacher at a private school \\
\hline Himal & Male & $\begin{array}{l}\text { Master's degree fourth semester } \\
\text { (Thesis ongoing) }\end{array}$ & No job \\
\hline Manjila & Female & $\begin{array}{l}\text { Master's degree fourth semester } \\
\text { (Thesis ongoing) }\end{array}$ & No job \\
\hline Manju & Female & Master's degree & $\begin{array}{l}\text { English teacher }(+2 \text { level }) \text { in a private } \\
\text { school }\end{array}$ \\
\hline Manoj & Male & $\begin{array}{l}\text { Master's degree fourth semester } \\
\text { (Thesis ongoing) }\end{array}$ & Helps family in their occupation \\
\hline Rachana & Female & $\begin{array}{l}\text { Master's degree fourth semester } \\
\text { (Thesis ongoing) }\end{array}$ & IELTS invigilator (part time) \\
\hline Shila & Female & $\begin{array}{l}\text { Master's degree fourth semester } \\
\text { (Thesis just started) }\end{array}$ & No job \\
\hline Vishnu & Male & $\begin{array}{l}\text { Master's degree fourth semester } \\
\text { (Thesis ongoing) }\end{array}$ & No job \\
\hline
\end{tabular}

The conventional gender-criterion was neglected for sampling in this research but, by coincidence, the number of male and female participants was the same ( 5 for each). It was ensured that the participants' (NMPOs') academic qualifications had not yet been fully materialized because they were still struggling for their career-related desire (i.e. not yet engaged with the job they were seeking for). In this sense, the NMPOs were still novice, so they would be a rich source of fresh personal narratives, something required as data for the study.

\subsection{The Data}

The stories obtained from the NMPOs via the e-mail were the basic data. Using an open-ended questionnaire as a tool (see Appendix), the subjective 'realities' rather than objective 'facts and figures' were elicited as the core data-texts in the form of 'biographical writing' (Savin-Baden \& Niekerk, 2007) from each of the NMPOs.

\subsection{Method of Analysis}

Content analysis technique was used to analyze the data; and thereby the emerging themes and patterns were identified, coded and categorized at different levels as appropriate. During the analysis of the stories and their write up, the principle of "a thick description of rich data" (Charmaz, 2006) was meticulously followed. Hence, the biographical narratives collected from the NMPOs were presented in readable texts.

\section{Results and Discussion}

The study was set out to derive answers to the three research questions (see Section 1; and, accordingly, a questionnaire (see Appendix) was administered to the NMPOs. The open-ended questions in the questionnaire were targeted basically at eliciting the participants' stories that would illustrate two fundamental aspects of the overall research theme: the NMPOs' expectations for learning ECS and their reflections on what they have achieved by learning it. Accordingly, the data have been analyzed, interpreted and discussed under three broad thematic headings and their subsequent sub-headings to match the research questions.

\subsection{Expectations for Learning ECS}

As the NMPOs' stories reveal, their expectations for learning ECS at the time they had joined Bachelor's degree, i.e., as BDCs, can be grouped under four sub-headings: job-and-career opportunities, comfortable and dignified life, interest and personal development, and academic practice and growth. 


\subsubsection{Job-and-Career Opportunities}

As revealed from the study of the participants' stories, most of the NMPOs seem to have initially perceived ECS as an investment that would capacitate them to obtain better job-and-career opportunities; thus, one of their expectations was associated with human capital development. When they had chosen ECS at the cost of any other subject(s) they could opt for, they had expected that, having completed their study in the subject, they would find a good job in Nepal easily. They had further expected that their academic achievement would make it easier for them to study abroad as part of their career development. Regarding this, Rachana narrates her story in this way: "I had expected that I would have more career opportunities in Nepal. I also thought it would make the way easier to study abroad as being proficient in English language."

Rachana's story is consistent with some of the previous findings that have reported the expectations of learners including 'getting higher and better-qualified jobs' (Zarrabi, 2018) in the Iranian context, 'having a better job/earning more money' (Akçay et al., 2015) in the context of Turkey, and 'socio-economic and professional gains' (Kandel, 2018) or 'English for employability' (Poudel, 2016) in the Nepalese context.

\subsubsection{Comfortable and Dignified Life}

Some of the participants, as it comes from the stories, had initially expected that ECS would serve them as a means of achieving a comfortable life with a higher social status. Dev narrates, "I initially thought that English would enable me to be a better person and help me lead a comfortable and dignified life after the completion of my study". Evidently, the words 'comfortable' and 'dignified' in Dev's story refer respectively to economic and social statuses to be attained by a person learned in English.

Dev's expectation for ECS is again somehow harmonious with the findings in the relevant literature, and shows that the learner is integratively motivated. Regarding the status of the English language prevailing in the Nepalese society three decades ago, Poudel (2019) remarks, "The name 'Major English' used to be a fame itself in our society, among friends, families and relations" (p. 3). Examining an NMPO's story, it occurs that the English-fame still seems afresh in Nepal. In a similar line, Manoj recalls, "My family members are only Nepali students. They don't know English. Only they know about are Sanskrit and Nepali. Therefore, I thought to start bringing changes to such kinds of traditional concepts by taking a new subject". Here it is inferable that Manoj had started his English-career with a motive of transforming himself into a unique member who possesses the knowledge of English among the knowers of Sanskrit and Nepali in the family. Differently, he had initially attached his personal dignity with the prestige of English.

\subsubsection{Interest and Personal Development}

Some of the stories seem to be neutral to any kind of 'instrumental' expectations for studying ECS, with the indication that learners' motivation towards the subject was somehow intrinsic. In those cases, the participants as BDCs had joined ECS without any specific expectation of benefits attached to English but simply due to their own interest or 'love of English', to borrow Zarrabi's (2018) code, which suggests that "it [English] sounds beautiful to them... a luxury" (p. 23). In this connection, an illustration comes from Himal, who narrates, "Well, initially, I joined English out of my love towards words and literature; mainly story writing and poetry". In a similar vein, Bimala's story suggests that she was unknowingly motivated towards English while being with and around the books in English that her sister used to have.

Such stories rather vaguely relate to the participants' opting for ECS. To take a few would be "to be more creative, and philosophical" (Himal); "to get insight into the complexities and nuances of our history and society" (Rachana); "to understand the society, world in a better way" (Vishnu); "I firmly believe in pursuing one's interest" (Shila); and "it [English] would be a threshold to the new world of literature, writing, criticism and many more" (Manju). In fact, such expressions disclose the participants' intrinsic motivation to personal development rather than any instrumental reward or benefit through ECS. The intense motivation towards the English language as perceived by the Nepalese society has been described by the local literature in various terms such as 'mania' (Bista, 2011), 'charm and attraction' (Kandel, 2018) and 'craze for English' (Poudel, 2018). In the expressions just mentioned, we can identify a variety of purposes for learning English - resulted from such a 'mania', 'charm' or 'craze' (whether stated explicitly or conveyed implicitly).

\subsubsection{Communicative Skills and Professional Development}

Some of the participants' stories are linked in some way with English for linguistically and professionally relevant development and growth of the learners, mostly in reading, writing, translation, literature and other creative fields. For instance, Manju's story goes in this way: ... "completion of Master's degree [in English] would be a threshold to the new world of literature, writing, criticism and many more". In a similar vein, Shila had 
expected that her qualification (Master's degree in ECS) would have been her asset as a journalist, a translator and a creator in other fields.

\subsection{Expectation-Achievement Links}

The stories disclose both attainments and unfulfilled dreams the participants had set initially as BDCs. The only participant who had started learning English without expecting anything in particular was Shila who states, "When I joined English I started as a blank slate with no expectations". However, as she claims, her later learning helped the growth of interest in the field. Deepak has achieved writing and presentation skills in consistency with his initial desire. As he looks up his own writing and presentation, he finds that he has adequately grown in these skills, though he states that he is "still working towards their fullest realization". Similarly, Himal, who had started with love for English- particularly story writing and poetry- has, in his own words ..."been attaining progress towards that goal". Likewise, Vishnu clarifies that he has read "[many of] the philosophical, creative texts of the best writers of the world .... and grabbed the power to understand the English language" but he is not fully satisfied with his writing skill itself.

A very significant clue some of the participants have left amid their stories is that English has given them social status/prestige but not enough of an economically comfortable life as expected before. Having completed his Master's degree in English, Dev, for example, has been "living a dignified life", which had been one of his initial expectations as a BDC, because, according to him, "people's perceptions towards him changed" but his expectation of "[economically] comfortable life...has just become a dream". Rachana's initial expectations were both integratively and instrumentally oriented - as expressed by her in terms of 'sound knowledge of the history of the English language and culture', and an 'easy access to career opportunities' respectively. As she thinks, the former has been fulfilled but the latter "...has been questioned" as she is "still struggling on the job market". Although Manjila has got a job of editing and translating in harmony with her expectation, she has not achieved as enough of speaking skills as she had expected earlier. Her story includes, "I am still working on pronunciation part". By studying ECS, Manju knew about the history of English and, in consistency with her initial expectation, she has now been an English teacher but she finds herself wrong in having expected that English would provide her with various opportunities. In different words, Manju has tolerably realized her integratively oriented expectation but her instrumental kind of expectation has only been partially met.

Bimala, who seems to have been integratively oriented towards learning ECS, is the one who claims that she has perfectly achieved what she had initially expected to do through ECS. She notes, "All my initial expectations have been achieved. Now I can read all those books. I can talk to a foreigner fluently in English".

In sum, the NMPOs have partially achieved what they had expected as BDCs when they had opted for ECS despite a few of the other choices open to them.

\subsection{Reflections on the Achievements}

At this point of discussion, we enlighten whether the NMPOs are satisfied with their achievements; and what suggestions they would extend to those who seek advice on whether to opt for ECS as a choice. Accordingly, the analysis has been presented under two sub-thematic categories: satisfactions/dissatisfactions, and suggestions for future ECS expectants.

\subsubsection{Satisfactions/Dissatisfactions}

The NMPOs have provided mixed responses to the query regarding whether they are satisfied with their achievements from learning English. On the surface, most of the stories reveal that the NMPOs are satisfied with what they have achieved through ECS. However, a few of them have also clearly disclosed their dissatisfactions, while some others have vaguely revealed their discontentment.

Bimala, who has now started a career as an English teacher, is perfectly satisfied with her achievements for more than just one reason. According to her, ECS has equipped her with the ability to read books in English and talk to foreigners, so it has disclosed her connection with "the world through English...world literature and getting to know diverse cultures, people and places" - which she was passionate of knowing. Likewise, Manoj is satisfied because he has developed fluency in English; and it has enabled him to "lecture at any college" now. Manju has been a composer and teacher of English which, to her, is "one of the powerful languages of the world". Shila expresses her view in these words: "I feel that I have earned saleable communicative and analytical skills".

Nonetheless, some of the NMPOs express their partial satisfaction with their achievements. Deepak remarks, "I am working towards their [expectations'] fullest realization", while Himal expresses “...to certain extent I have been attaining progress towards that goal". In the same vein, Vishnu expresses his partial satisfaction thus, "...to some extent...I am satisfied with my achievement from learning English. But what I believe is knowledge is 
never sufficient... The more you gain, [the] more you have hunger of it". These parts of the stories indicate, though vaguely, that English has prepared the NMPOs for potential achievements- as they only hopefully believe.

On the other extreme, some stories clearly demonstrate the NMPOs' dissatisfactions. In her story, Rachana clarifies her position in this way: "My sanguine attitude on the availability of career opportunities has been questioned as I am struggling on the job market recently". Her dissatisfaction bears a close approximation with the instrumental orientation because she regrets, "I am not satisfied with my achievements from learning English. So I am thinking of taking another degree on [in] social science area considering English only as a base or foundation". Dev seems to be aligned with the human capital theory when he critically complains that, for him, ECS has been rather an idealistic investment without an immediate happy return for his practical life as a member of 'this capitalist society'. He states “...but I am not happy. Because reading English [alone] in this capitalist society does not help us lead a prosperous and happy life." Without stating any clear reason, Manoj expresses his dissatisfaction in a bit round-about language thus: "I would not say I am satisfied with my achievements from learning English because I have not yet met all my expectations that I initially thought I would be able to meet after completion of my study".

\subsubsection{Suggestions for Future ECS Expectants}

As an attempt to elicit some salient suggestions, a query was employed to seek what the NMPOs would like to suggest for those opting to opt for ECS in the future. This section is devoted to the discussion on those suggestions stemming from their responses.

Two of the NMPOs would stand strongly for advising in favour of choosing ECS. Manoj would do so, as he thinks, "without English language you cannot do anything in your coming future". In the meantime, as Bimala suggests, one should opt for it because "it would pave path to multiple career opportunities in diverse fields including tourism, industry and so on". Their suggestions evidently align with instrumentality and are even inclined to education as human capital investment. At the same time, they are also consistent with Eshghinejad's (2016) observation that "the nature of language learning...depends primarily on learners' motivation and attitude to learning a target language" (p. 3). In consistency with integrative orientation, Himal suggests that if one's goal is close to ("not...pole-opposite to"- to use his own words) creativity, art, literature and ideology, one had better opt for ECS.

However, most of the other NMPOs' suggestions have reservations. Rachana would explain the situation of the current job market and advise one to "take training or other course besides English as a major subject so that they won't have to face the problematic situation of finding a right career as an English graduate"-an opinion oriented to instrumentality. Similarly, Dev would advise one to opt for ECS only if one is from "a rich background and is not worried about a job or property", but not otherwise. As Vishnu thinks, one's motivation counts. He justifies, "Because one can give his/her best where their interest lies". In a similar vein, Shila suggests that one can take ECS if one is "passionate about literature and linguistic crafts"; but for this all "What you need is rigorous practice", remarks Manjila. In Shila's opinion, ECS should be made 'more charming' by supplementing it with such 'hard skills' as translation, editing and proofreading for "preparing students in the competitive market", a view clearly consistent with human capital investment. Finally, very close to human capital theory, a penny drops from Rachana: "choosing other fields of study would be [an] ideal choice to succeed as a professional scholar" rather than opting for ECS at all.

\section{Conclusion}

As assumed earlier in this study, almost all of the participants had opted for ECS with varied expectations some of which are explicable in line with intrinsic motivation such as 'love of English', particularly 'literature', 'poetry', 'composition', 'philosophy' and 'criticism'. Similarly, some had started learning ECS with expectations oriented towards some sorts of integrative ends, that is, for an exposure to the understanding of the vast world through its society, history and culture. In these respects, they were somehow satisfied- two of them with full satisfaction- with their achievements. Nevertheless, the claim that literature could be a genuine source for learning 'society', 'philosophy', 'history' and 'culture' might be misleading.

A very practical as well as critical aspect for the policy would be the participants' dissatisfactions which are instrumentally oriented. It is sensitive that nearly all participants question their own achievements overtly or covertly with the dissatisfaction that even having completed the Master's degree with ECS they are still worried about their unemployment. To take a case, one of the participants has even decided to make a new start with a social science subject for her future career with an expectation that her qualification would be more easily saleable in the market. In a similar vein, another participant conveys his realization that, being idealistic rather than practical, English alone would not help obtain prosperity in today's capitalist world. 
The participants' stories also include suggestions for the to-be English majors. Only two of them are fully satisfied with their achievements from learning ECS and think it as a cure-all for the future generation. They doubt that their qualification in English would be the right choice for multiple opportunities such as tourism and industry. There also have some suggestions which indicate the need for improving the course in line with easily available employability which could be achieved by incorporating in the English syllabus such 'hard skills' as training, editing, translating and proofreading so that the NMPOs would be more readily saleable in the job market. Otherwise, to restate a participant's view, "choosing other fields of study would be an ideal choice to succeed as a professional scholar".

Finally, considering the results, we, the researchers, would like to take liberty to suggest that, to maintain its 'charm' and 'attraction' even in the future, the authority should review ECS with the essence of human capital theory, that is, education as investment, in mind.

\section{Acknowledgements}

We, the authors, cordially acknowledge the following:

- University Grants Commission (UGC), Nepal for funding this paper's publication; and

- Raj Kumar Baral, Lecturer, Tribhuvan University, Central Department of English, for his advice on the appropriateness of the participants during participant selection as well as his co-operation during data collection.

\section{Conflict of Interest}

The study on which this paper is based was undertaken solely by the authors and was not funded by any agency.

\section{References}

Abrar-Ul-Hassan, Shahid. (2014). A study of the motivational patterns of learners of English for academic and professional purposes. TESOL Journal, 5(1), 32-56. https://doi.org/10.1002/tesj.74

Akçay, Aslıhan, Tuba Ferzan Bütüner, \& Arda Aikan. (2015). Reasons behind young learners' learning of foreign languages. International Journal of Language Academy, 3(2), 56-68. https://doi.org/10.18033/ijla.231

Barkhuizen, Gary. (2015). Narrative inquiry. In Brian Paltridge \& Aek Phakiti (Eds.), Research methods in applied linguistics (pp. 169-185). London: Bloomsbery Academic.

Bista, Krishna. (2011). Teaching English as a foreign/second language in Nepal: Past and present. English for Specific Purposes World, 11(32), 1-9. Retrieved from https://files.eric.ed.gov/fulltext/ED530898.pdf

Charmaz, Kathy. (2006). Constructing grounded theory. London: Sage Publications.

Daif-Allah, Ayman Sabry. (2012). Beliefs about foreign language learning and their relationship to gender. English Language Teaching, 5(10), 20-33. https://doi.org/10.5539/elt.v5n10p20

Dörnyei Zoltán, \& Ema Ushioda. (2011). Teaching and researching motivation. Harlow: Pearson Education Ltd.

Dörnyei, Zoltan. (1974). Motivation and motivating in the foreign language classroom. The Modern Language Journal, 78(3), 273-284. https://doi.org/10.1111/j.1540-4781.1994.tb02042.x

Eshghinejad, Shahrzad. (2016). EFL students' attitudes toward learning English language: The case of Kashan University students. Cogent Education, 3, 1-13. https://doi.org/10.1080/2331186X.2016.1236434

Harmer, Jeremy. (2008). How to teach English. Harlow: Pearson Education Ltd.

Howitt, Dennis. (2016). Qualitative research methods in psychology (3rd ed.). Harlow: Pearson Education.

Kandel, Basanta. (2018). The charm and attraction of English language to Nepali students. Discovery Dynamics, $4(2), 1-11$.

Karimi, Mohammad Nabi, \& Samane Saddat Hosseinei Zade. (2018). Teachers' use of motivational strategies: effects of a motivated teacher development course. Innovation in Language Learning and Teaching, 13(2), 194-204. https://doi.org/10.1080/17501229.2017.1422255

Lamb, Martin. (2016). When motivation research motivates: Issues in long-term investigations. Innovation in Language Teaching and Learning, 12(4), 357-370. https://doi.org/10.1080/17501229.2016.1251438

Lindahl Mikel, \& Erik Canton. (2007). The social returns to education. In Joop Hartog \& Heriëtte Maassen van den Brink (Eds.), Human capital: Theory and evidence (pp. 21-37). Cambridge: Cambridge University Press. https://doi.org/10.1017/CBO9780511493416.003 
Nafukho Fredrick Muyia, Nancy R. Hairston, \& Kit Brooks. (2004). Human capital theory: Implications for human resource development. Human Capital Resource Development International, 7(4), 545-551. https://doi.org/10.1080/1367886042000299843

Noels, K., R. Clement, \& L. Pelletier. (1999). Perceptions of teachers' communicative style and students' intrinsic and extrinsic motivation. Modern Language Journal, 83, 23-34. https://doi.org/10.1111/0026-7902.00003

Poudel, Kamal Kumar. (2016). B. Ed. first year students' expectations implied in learning English. Education and Development (CERID), 27, 146-155.

Poudel, Kamal Kumar. (2018). An English language bridge course as a project outcome. International Journal of Science and Research, 7(12), 118-122.

Poudel, Kamal Kumar. (2019). Nativizing English as a foreign language with local linguistico-cultural expressions: Classroom applications and wider implications. In Terrel Weltch (Ed.), Foreign langauge teaching and learning: New research (pp. 1-59). New York: Nova Press.

Privitera, Gregory J., \& Lynn Ahlgrim-Delzell. (2019). Research methods for education. California: Sage Publications.

Savin-Baden, Maggi, \& Lana Van Niekerk. (2007). Narrative inquiry: Theory and practice. Journal of Geography in Higher Education, 31(3), 459-472. https://doi.org/10.1080/03098260601071324

Sieglová, Dagmar. (2019). From motivation to successful learning: Needs analysis for effective teaching. Language Learning in Higher Education, 9(2), 429-443. https://doi.org/10.1515/cercles-2019-0023

Zarrabi, Fatemeh. (2018). English in an EFL context: Teachers' and learners' motivations for English language learning. English Language Teaching, 11(9), 17-25. https://doi.org/10.5539/elt.v11n9p17 


\section{Appendix: Questionnaire}

Please respond to the following queries related to English as your career subject.

1) What had you initially thought English would enable you to do on completion of your study?

2) Which of your initial expectations have you achieved and which of them not?

3) Are you satisfied with your achievements from learning English? Why or why not?

4) If someone beginning his/her career in higher education asked you "Shall I take Major English?" what would be your suggestions to him/her? Why?

5) Do you have anything further to say?

\section{Copyrights}

Copyright for this article is retained by the author(s), with first publication rights granted to the journal.

This is an open-access article distributed under the terms and conditions of the Creative Commons Attribution license (http://creativecommons.org/licenses/by/4.0/). 